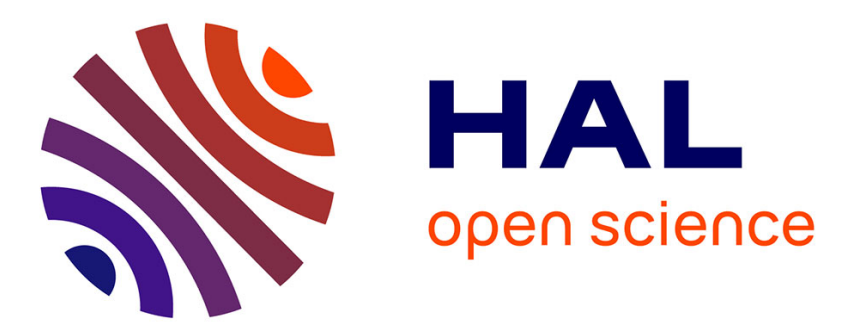

\title{
A submesoscale coherent vortex in the Ligurian Sea: From dynamical barriers to biological implications
}

\author{
Anthony Bosse, Pierre Testor, Nicolas Mayot, Louis Prieur, Fabrizio \\ d'Ortenzio, Laurent Mortier, Hervé Le Goff, Claire Gourcuff, Laurent \\ Coppola, Héloïse Lavigne, et al.
}

\section{To cite this version:}

Anthony Bosse, Pierre Testor, Nicolas Mayot, Louis Prieur, Fabrizio d'Ortenzio, et al.. A submesoscale coherent vortex in the Ligurian Sea: From dynamical barriers to biological implications. Journal of Geophysical Research. Oceans, 2017, 122 (8), pp.6196 - 6217. 10.1002/2016JC012634 . hal-01621729

\section{HAL Id: hal-01621729 \\ https://hal-amu.archives-ouvertes.fr/hal-01621729}

Submitted on 15 Feb 2021

HAL is a multi-disciplinary open access archive for the deposit and dissemination of scientific research documents, whether they are published or not. The documents may come from teaching and research institutions in France or abroad, or from public or private research centers.
L'archive ouverte pluridisciplinaire HAL, est destinée au dépôt et à la diffusion de documents scientifiques de niveau recherche, publiés ou non, émanant des établissements d'enseignement et de recherche français ou étrangers, des laboratoires publics ou privés. 


\section{A submesoscale coherent vortex in the Ligurian Sea: from dynamical barriers to biological implications} Anthony Bosse ${ }^{1,2}$, Pierre Testor ${ }^{2}$, Nicolas Mayot ${ }^{3}$, Louis Prieur ${ }^{3}$, Fabrizio D'Ortenzio $^{3}$, Laurent Mortier ${ }^{4,2}$, Hervé Le Goff ${ }^{2}$, Claire Gourcuff ${ }^{5,2}$, Laurent Coppola $^{3}$, Héloïse Lavigne ${ }^{6}$, Patrick Raimbault ${ }^{6}$

Corresponding author: A. Bosse, University of Bergen, Geophysical Institute, Allégaten 70, 5007 Bergen, Norway (anthony.bosse@uib.no)

${ }^{1}$ University of Bergen and Bjerknes 


\section{Abstract.}

${ }_{4} \quad$ In June 2013, a glider equipped with oxygen and fluorescence sensors has

${ }_{5}$ been used to extensively sample an anticyclonic Submesoscale Coherent Vor-

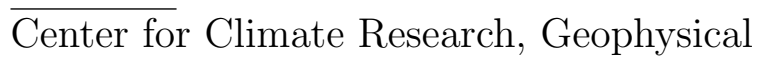

Institute, Allégaten 70, 5007 Bergen,

Norway.

${ }^{2}$ Sorbonne Universités (UPMC, Univ

Paris 06)-CNRS-IRD-MNHN, Laboratoire

LOCEAN, 4 place Jussieu, F-75005 Paris,

France.

${ }^{3}$ Sorbonne Universités (UPMC, Univ

Paris 06)-CNRS, Laboratoire

d'Océanographie de Villefranche, F-06230

Villefranche/mer, France.

${ }^{4}$ ENSTA Paristech, Palaiseau, France

${ }^{5}$ Euro-Argo ERIC, Brest, France

${ }^{6}$ Istituto Nazionale di Oceanografia e di

Geofisica Sperimentale - OGS, Trieste, Italy

${ }^{7}$ Aix-Marseille University, Sud Toulon-Var

University, CNRS/INSU, IRD, MIO,

Marseille, France 
6 tex (SCV) in the Ligurian Sea (NW Mediterranean Sea). Those measurements

7 are complemented by full-depth CTD casts (T, S, Oxygen) and water sam-

s ples documenting nutrients and phytoplankton pigments within the SCV and

9 outside. The SCV has a very homogeneous core of oxygenated waters between

$10300 \mathrm{~m}$ and $1200 \mathrm{~m}$ formed 4.5 months earlier during the winter deep con-

11 vection event. It has a strong dynamical signature with peak velocities at

${ }_{12} 700 \mathrm{~m}$ depth of $13.9 \mathrm{~cm} \mathrm{~s}^{-1}$ in cyclogeostrophic balance. The eddy has a small

13 radius of $6.2 \mathrm{~km}$ corresponding to high Rossby number of -0.45 . The vor-

${ }_{14}$ ticity at the eddy center reaches $-0.8 f$. Cross-stream isopycnic diffusion of

15 tracers between the eddy core and the surroundings is found to be very lim-

${ }_{16}$ ited due to dynamical barriers set by the SCV associated with a diffusivity

${ }_{17}$ coefficient of about $0.2 \mathrm{~m}^{2} \mathrm{~s}^{-1}$. The deep core is nutrients-depleted with con-

${ }_{18}$ centrations of nitrate, phosphate and silicate $13-18 \%$ lower than the rich sur-

19 rounding waters. However, the nutriclines are shifted of about 20-50 m to-

${ }_{20}$ ward the surface thus increasing the nutrients availability for phytoplank-

${ }_{21}$ ton. Chlorophyll-a concentrations at the deep chlorophyll maximum are sub-

${ }_{22}$ sequently about twice bigger as compared to outside. Pigments further re-

23 veal the predominance of nanophytoplankton inside the eddy and an enhance-

${ }_{24}$ ment of the primary productivity. This study demonstrate the important im-

${ }_{25}$ pact of post-convective SCVs on nutrients distribution and phytoplankton

${ }_{26}$ community, as well as on the subsequent primary production and carbon se-

${ }_{27}$ questration. 


\section{Introduction}

The northwestern Mediterranean Sea is one the few particular places of the world's oceans, where intense atmospheric forcing combined to a weak ocean stratification allows vertical mixing to reach depths $(>1500-2000 \mathrm{~m})$. This phenomenon is called open-ocean deep convection and is of critical importance for the ventilation of the deep oceans and 32 has been studied since the 1970s (see Marshall and Schott [1999] for a review). It can be 3з divided into three main phases (that however overlap in space and time) [MEDOC-Group, 34 1970]: the preconditioning consisting in a basin-scale cyclonic circulation causing a doming 35 of isopycnals at its center; the mixing phase, which results from cold and dry winds blowing ${ }_{36}$ over the preconditioned area leading to intense heat losses of the ocean and a deepening ${ }_{37}$ of the mixed layer (typically several hundreds of watts per squared meter for a couple of 38 days [Leaman and Schott, 1991]); the spreading phase induced by the restratification of the 39 water column that occurs, when the intense heat losses cease (generally in early spring). 40 During this last phase, the mixed patch of convected waters breaks up into numerous ${ }_{41}$ eddies by conversion of potential energy into kinetic energy through baroclinic instability ${ }_{42}$ [Gascard, 1978; Legg and Marshall, 1993; Visbeck et al., 1996; Jones and Marshall, 1997].

${ }_{43}$ In particular, Submesoscale Coherent Vortices are formed [McWilliams, 1985]. They ${ }_{44}$ are characterized by a small radius, subsurface peak velocities and an extended lifetime

${ }_{45}$ ( $>1$ year). They were found to be involved in the large-scale spreading of newly-formed ${ }_{46}$ deep waters toward the western Mediterranean Sea [Testor and Gascard, 2003, 2006], the ${ }_{47}$ Greenland Sea [Gascard et al., 2002] and the Labrador Sea [Lilly and Rhines, 2002]. In ${ }_{48}$ the western Mediterranean Sea, this process has been recognized as being particularly 
${ }_{49}$ important: SCVs could transport $30-50 \%$ of the newly formed deep waters out of the

so convective zone [Testor and Gascard, 2006; Bosse et al., 2016; Damien et al., in revision,

${ }_{51}$ this issue], while another important part could be transported by the mean circulation

${ }_{52} \quad[$ Send et al., 1996].

${ }_{53} \quad$ The strong rotation of SCVs sets transport barriers at that drastically reduce the lateral ${ }_{54}$ exchanges between their deep core and the surrounding waters [Rhines and Young, 1983;

${ }_{55}$ Provenzale, 1999]. As a consequence, they are therefore extremely efficient in transport-

${ }_{56}$ ing physical and biogeochemical tracers characteristics of their generation site over long ${ }_{57}$ distances [D'Asaro, 1988; Testor and Gascard, 2003; Bower et al., 2013]. As a conse${ }_{58}$ quence, they can greatly impact the biogeochemical cycles at a local scale. For instance, ${ }_{59}$ Budéus et al. [2004] reported a significant increase in the bacteria abundance at great ${ }_{60}$ depths within a deep SCVs observed in the Greenland Sea. Durrieu de Madron et al. ${ }_{61}^{6}$ [2017] reveal sediments being trapped within cyclonic SCVs in the NW Mediterranean ${ }_{62}$ Sea. In oxygen depleted oceans, they have been identified as local spots for denitrification ${ }_{63}$ [Löscher et al., 2015; Karstensen et al., in review, 2016] and habitat compression due to ${ }_{64}$ their very low oxygen content [Lachkar et al., 2016]. Especially in tropical oceanic basins, ${ }_{65}$ subsurface eddies can be tentatively be detected from space when combined with infrared ${ }_{6}$ satellite images [Klemas and Yan, 2014], even though the surface expression of deep sub${ }_{67}$ surface eddies is often small [Ciani et al., 2015]. In the Mediterranean Sea, as well as in ${ }_{68}$ high latitude environment characterized by small deformation radii of 5-10 km, sampling

${ }_{69}$ the fine scale of eddies remnant of wintertime convection is thus very challenging.

70 By allowing a relatively high horizontal resolution (distance between consecutive profiles ${ }_{71} \quad 2-4 \mathrm{~km}$ ), autonomous gliders could characterize the dynamics of post-convective SCVs of 
${ }_{72}$ about $10 \mathrm{~km}$ in diameter observed in the NW Mediterranean Sea [Bosse et al., 2016].

73 Winter 2013 was an intense convective year that produced many vortical structures. In

74 this study, we analyze in situ observations collected during summer 2013 in the Ligurian

${ }_{75}$ Sea by a research vessel and a glider in the same SCV. About 10 days after the first

76 survey by the $\mathrm{R} / \mathrm{V}$, the glider met by pure luck the same eddy around $30 \mathrm{~km}$ to the

77 southwest from the first observation. Both observations have very high similarities in

78 their vertical structure and are separated by a relative close distance in space and time in

79 coherence with the typical drift of SCVs. The intense sampling of the upper $1000 \mathrm{~m}$ by the

so glider combined with full-depth CTD casts and water samples documenting the nutrients

${ }_{81}$ concentrations, as well as phytoplankton pigments enable the first detailed study of such

${ }_{82}$ a small-scale post-convective vortex.

\section{Data and methods}

\subsection{Basin-scale cruise}

Since 2010, sustained observations of the circulation and water properties are carried

${ }_{84}$ out within the framework of the MOOSE project (NW Mediterranean Sea Observatory:

${ }_{85}$ http://www.moose-network.fr/). The MOOSE-GE cruises aim at providing a yearly snap-

${ }_{86}$ shot in summer of the open-ocean part of the basin with about 70-100 CTD stations. As

${ }_{87}$ an important part of this integrated ocean observing system, gliders are also regularly

${ }_{88}$ deployed in the whole sub-basin along repeated sections. The common key objective of

${ }_{89}$ the MOOSE observatory is to monitor the deep waters formation in the Gulf of Lions in

${ }_{90}$ order to assess its effect on biogeochemical cycles, and on the longer-term environmental

${ }_{91}$ and ecosystemic trends and anomalies [Durrieu de Madron et al., 2011]. 
94 revision, this issue].

95

96

Hydrographical data: In February 2013, the DEWEX leg 1 was carried out in the NW Mediterranean Sea [Testor, 2013]. With 75 CTD casts distributed over the whole basin, it enables to get a precious picture of the winter deep convection at its climax (see figure 1). In June-July 2013, 72 CTD stations have been collected during the MOOSEGE 2013 cruise [Testor et al., 2013]. A profile revealed the presence of a subsurface vortex in the Ligurian Sea (see figure 2). The conductivity, temperature and pressure measurements during those two cruises have been performed using a Seabird SBE911+ CTD probe. The CT sensors have been calibrated by pre- and post-deployment laboratory analysis. After calibration, the absolute accuracy of the measurements is 0.003 for the salinity and $0.001^{\circ} \mathrm{C}$ for the temperature. These calibrated CTD casts provide a ground truth for the autonomous underwater gliders.

Lowered ADCP (LADCP): During the MOOSE-GE 2013 cruise, the rosette was carrying two RDI WH $300 \mathrm{khz}$ LADCPs (up and down looking). 61 LADCP profiles were processed with the LDEO V8b code based on the inversion method developed by Visbeck [2002]. All profiles were inversed at $8 \mathrm{~m}$ vertical resolution using both instruments from the surface to the bottom, navigation data from the CTD file and bottom track constraint when available. Precision on horizontal velocities range from 2 to $4 \mathrm{~cm} \mathrm{~s}^{-1}$ for all validated profiles. Here, we use the LADCP profile carried within the eddy (leg 1, station 7).

Dissolved oxygen: The rosette was equipped with a SBE43 sensor for dissolved Oxygen (DO), which has been calibrated before the cruises operation and after with 
115 post-cruises manufacturer calibrations. After calibration, the absolute accuracy of the

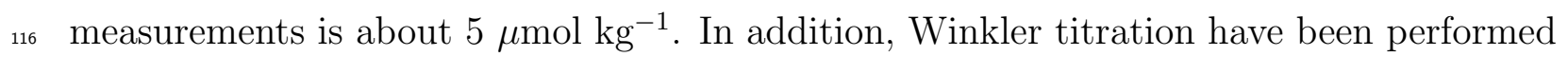
${ }_{117}$ on board after seawater sampling. The measurements have been done each day (every 4-5 ${ }_{118}$ stations) and the SBE43 sensor has been cleaned after each CTD cast following the manu119 facturer recommendations [Janzen et al., 2007]. Later on, the Winkler analysis have been used to adjust the SBE43 raw data, as specified by the GO-SHIP group (http://www.go${ }_{121}$ ship.org/).

${ }_{122}$ Nutrients: Water samples for nitrate, nitrite, phosphate and silicic acid determina${ }_{123}$ tion were collected from the Niskin bottles into $20 \mathrm{~mL}$ polyethylene flasks and immediately ${ }_{124}$ poisoned with $10 \mu \mathrm{g} \mathrm{L}^{-1}$ mercuric chloride and stored for subsequent laboratory analy${ }_{125}$ sis following Kirkwood [1992]. Nitrate $\left(\mathrm{NO}_{3}^{-}\right)$, phosphate $\left(\mathrm{PO}_{4}^{3-}\right)$ and silicate $\left(\mathrm{Si}(\mathrm{OH})_{4}\right)$ ${ }_{126}$ ions were analyzed in laboratory by standard automated colorimetric system using a Seal ${ }_{127}$ Analytical continuous flow AutoAnalyser III according to Aminot and Kérouel [2007]. In${ }_{128}$ house standards regularly compared to the commercially available products (OSIL) were used to ensure the reproducibility of the measurements between the analyses.

Dissolved Inorganic Carbon: For $C_{T}$ (or DIC) measurements, seawater samples were collected into washed $500 \mathrm{~mL}$ borosilicate glass bottles, and poisoned with 132 a saturated solution of $\mathrm{HgCl}_{2}$. At the end of the cruise, the samples were sent 
Pigments: The vertical distribution of phytoplankton pigment concentrations was determined through discrete water samples collected with Niskin bottles mounted on the CTD rosette. The discrete water samples were then filtered (GF/F) and High-Performance Liquid Chromatography (HPLC) analyses have been performed to provide a precise determination of the different phytoplankton pigments concentrations. All HPLC measurements used here were conducted at the Laboratoire dÓcéanographie de Villefranche (see Ras et al. [2008] for details on the HPLC method). As in Mayot et al. [submitted, this issue], we used the pigment-based approach proposed by Claustre [1994] and further improved by Vidussi et al. [2001] and Uitz et al. [2006] to estimate the contribution of three phytoplankton size classes: micro-, nano-, and pico-phytoplankton (respectively, $f_{\text {micro }}$, $f_{\text {nano }}$ and $\left.f_{\text {pico }}\right)$ to the total phytoplankton biomass estimated as $\left[C h l_{a}\right]$ the chlorophyll-a concentration. Seven diagnostic pigments were selected as biomarkers of major phytoplankton taxa: fucoxanthin $([$ Fuco $])$, peridinin $([$ Perid $])$, alloxanthin $([$ Allo $])$, 19'butanoyloxyfucoxanthin ([ButFuco $]$ ), 19'-hexanoyloxyfucoxanthin ([HexFuco $]$ ), zeaxanthin $([Z e a])$ and total chlorophyll-b (chlorophyll-b + divinyl chlorophyll-b $\left.=\left[T C h l_{b}\right]\right)$ to compute fmicro, fnano, and fpico:

$$
\begin{aligned}
f_{\text {micro }} & =(1.41[\text { Fuco }]+1.41[\text { Perid }]) / \sum D P W \\
f_{\text {nano }} & =(1.27[\text { HexFuco }]+0.35[\text { ButFuco }]+0.60[\text { Allo }]) / \sum D P W \\
f_{\text {pico }} & =\left(1.01\left[\text { TCh } l_{b}\right]+0.86[\text { Zea }]\right) / \sum D P W
\end{aligned}
$$

154 with $\sum D P W$ a weighted sum of the seven diagnostic pigments concentration: $D P W=$ $\left(1.41[\right.$ Fuco $]+1.41[$ Perid $]+1.27[$ HexFuco $]+0.35[$ ButFuco $]+0.60[$ Allo $]+1.01\left[\right.$ TChl $\left._{b}\right]+$ $0.86[Z e a])$. Eventually, the phytoplankton classspecific vertical profiles of chlorophyll-a were deduced by: $\left[C h l_{a}\right]_{\text {class }}(z)=\left[C h l_{a}\right](z) f_{\text {class }}(z)$. 


\subsection{Remote sensing}

\subsection{SCV reconstruction}

order to minimize the difference between the glider optode and calibrated shipborne measurements. The comparison is made with CTD casts carried out at less than $50 \mathrm{~km}$ and 2 days apart from glider measurements for the winter mission and with profiles carried out in the SCV core for the summer deployment. After this calibration procedure the RMS difference between the glider and shipborne measurements at depth was respectively 1.5 and $1.3 \mu \mathrm{mol} \mathrm{kg}{ }^{-1}$, which is below the accuracy of absolute shipborne measurement.

Chl-a Fluorescence: The glider also had a Wet Labs bio-optical fluoremeter. Unfortunately, no direct comparison with HPLC measurements was possible with the glider data, as the short response time of phytoplankton growth imposes a very close match-up in space and time. Alternatively, a calibration method using satellite ocean color was applied [Lavigne et al., 2012]. In this calibration step, fluorescence profiles were also corrected for non-photochemical quenching following Xing et al. [2012]. With a larger dataset, Mayot et al. [in revision, this issue] tested this method against bottle measurements. Both calibrations gave satisfying and similar results (Mean Absolute Deviation Percent of 23\% with HPLC and $38 \%$ with satellite), thus supporting the use of the method of Lavigne et al. [2012] when direct comparison with in situ data is not possible.

Surface chlorophyll concentration from level 2 MODIS Aqua product (daily and at $1 \mathrm{~km}$ resolution) were extracted over the northwestern Mediterranean Sea from the NASA web site (http://oceancolor.gsfc.nasa.gov/). All the MODIS L2 flags have been applied.

\subsubsection{Vortex center detection}


${ }_{246} 1000 \mathrm{~m}$ and only two full-depth shipborne profiles below. The shipborne CTD cast within 
the amplitude of cyclogeostrophic velocities are smaller (respectively larger) than $v_{g}$ for cyclones (resp. anticyclcones). To infer cyclostrophic velocities, absolute geostrophic velocities have thus to be determined first.

Classically, the cross-track geostrophic vertical shear is computed by integrating the thermal wind balance from a smoothed density section. Here, we applied a Gaussian moving average of $3.2 \mathrm{~km}$ variance (half of the eddy radius) to the analyzed density field to filter out residual small-scale isopycnals variability without fading the SCV signature. The cut-off length scale is set in accordance with the vortex radius. A modal decomposition on typical density profiles consistently yields a first baroclinic deformation radius of about $6 \mathrm{~km}$. This is relatively small compared to other oceans owing to the low stratification of the northwestern Mediterranean Sea.

For a Gaussian geopotential anomaly, the orbital velocities of the SCV can be written as: $V(r)=V_{0} \frac{r}{r_{0}} e^{-\left[\left(\frac{r}{r_{0}}\right)^{2}-1\right] / 2}$ where $V_{0}$ corresponds to the velocity maximum located at the distance $r_{0}$ from the center [McWilliams, 1985; Pingree and Le Cann, 1993]. We performed a least squares fit of this Gaussian model to the total DAC from the glider in order to estimate $V_{0}\left(=12.2 \pm 2.2 \mathrm{~cm} \mathrm{~s}^{-1}\right)$ and $r_{0}(=6.3 \pm 0.2 \mathrm{~km})$. Observations and parametrized velocity show a good agreement with velocities decreasing close to zero within about three radii (see figure 3-b).

Then, the geostrophic component of total depth-average currents is computed following Bosse et al. [2016], so the geostrophic shear can be correctly referenced from the surface to $1000 \mathrm{~m}$ depth (see details in appendix of the latter reference). This method applies when ageostrophy is due to the centrifugal force, which is particularly relevant for small-scale 
$\left.{ }_{311} \quad R o(r, z)\right) / g$. 


\subsection{Lateral isopycnic diffusion}

${ }_{321}$ its anomalous concentration until reaching $T_{\infty}$.

322

323 
${ }_{334}$ salinity gradients vanish close to its equilibrium depth making diffusion estimate impos-

\section{Results}

\subsection{Water mass transformation during winter 2013}


355 oxygen minimum when they reach the Western Mediterranean Sea (see figure 1-d and 2-d).

${ }_{356}$ The Western Mediterranean Deep Waters (WMDW) eventually fill the rest of the water

${ }_{357}$ column to the bottom. Due to its relative small overturning timescale, the Mediterranean

${ }_{358}$ Sea is highly sensitive to climate change [Somot et al., 2006]. The heat and salt contents

359 of the deep waters have been gradually increasing during the last decades [Béthoux et al., 1990; Krahmann and Schott, 1998], with step-like events caused by major deep convection

${ }_{361}$ events [Schroeder et al., 2016; Houpert et al., 2016].

${ }_{362}$ In addition to AW, LIW and WMDW, other less widespread water masses are found.

${ }_{363}$ The Winter Intermediate Waters (WIW), which result from intermediate mixing down 364 to about $300 \mathrm{~m}$ maximum (above the LIW layer) in open-ocean [Gasparini et al., 2005] 365 or in shelf areas of the Gulf of Lions [Juza et al., 2013] or the Catalan Sea [Vargas${ }_{366}$ Yáñez et al., 2012]. They are classically characterized by potential temperature below ${ }_{367} 13^{\circ} \mathrm{C}$. Recently, Bosse et al. [2016] introduced an additional water mass to complete this 368 picture. Intermediate mixing can indeed result in the episodic formation intermediate ${ }_{369}$ waters below the LIW layer at about 500 to $1000 \mathrm{~m}$ depth. This water mass lies deeper 370 than WIW and is also much warmer $\left(>13^{\circ} \mathrm{C}\right)$ and saltier $(>38.5)$, as a result of the ${ }_{371}$ mixing of the elevated heat and salt contents of the LIW layer. It has been called Winter ${ }_{372}$ Deep Waters (WDW). Favorable conditions to its formation were observed in 2012 and 2013 in the Ligurian Sea [Bosse et al., 2016], as well as in 2014 and 2015 in the Gulf of ${ }_{374}$ Lions [Bosse, 2015].

\section{3.1 .2 . Winter mixing in the Ligurian Sea}

The glider mission MOOSE T00-23 sampled the Ligurian Sea from January to March ${ }_{377}$ at the climax of the deep convection. The figure 1-c shows the progressive deepening 
378 of the mixed layer (defined using the refined criterion of Houpert et al. [2016]). As seen

379 by the glider along the Nice-Calvi section, the mixed layer reaches a maximum depth of 380 about $800 \mathrm{~m}$ between the $13^{\text {th }}$ and $16^{\text {th }}$ of February (see figure 1-c). Shipborne CTD casts 381 were taken along the same section a few days later on February 19 and 20, while surface 382 layers had already started to restratify after an intense wind event. However, CTD casts звз collected slightly southwest of the glider section revealed comparable deep mixed layers.

${ }_{384}$ This illustrates the high spatial and temporal variability of the convective area. The 385 center of the Ligurian Sea convective zone could have been located slightly southwest of ${ }_{386}$ the Nice-Calvi glider section, as also suggested by satellite images (see figure 8 in Houpert ${ }_{387}$ et al. $\left.[2016]\right)$.

${ }_{388}$ In terms of hydrographical characteristics, when the mixed layer was observed deeper 389 than $600 \mathrm{~m}$, it was characterized by a mean potential temperature close to $13.17^{\circ} \mathrm{C}$ and 390 practical salinity close to 38.54 . In a $\theta / S$ diagram, this water mass lies on the mixing line 391 between LIW and WMDW and can be qualified as Winter Deep Waters following Bosse ${ }_{392}$ et al. [2016]. The mixed layer was observed to be deeper than $600 \mathrm{~m}$ in the Gulf of Lions 393 and characterized by colder and fresher characteristics of the newly formed WMDM (see 394 figure 1-b).

\subsection{SCV characteristics}

\subsubsection{Hydrographical description}

During the MOOSE-GE 2013 cruise, a CTD cast carried out in the Ligurian Sea on ${ }_{397}$ June 15 revealed a particularly homogeneous layer of oxygenated waters between $300 \mathrm{~m}$ 398 and $1200 \mathrm{~m}$ depth $\left(\theta \sim 13.18^{\circ} \mathrm{C}, S_{P} \sim 38.54\right.$, DO $=195-200 \mu \mathrm{mol} \mathrm{kg}^{-1}$, see figure 399 2-b). Shortly after, a glider deployed along the repeated "Nice-Calvi" endurance line 
${ }_{400}$ (mission MOOSE T00-26) crossed by chance the same water mass (see figure 2-c). From

401600 to $900 \mathrm{~m}$, potential temperature only increases by $0.0014^{\circ}$ and salinity by 0.0015 .

${ }_{402}$ The resulting vertical stratification is very weak: $+0.0005 \mathrm{~kg} \mathrm{~m}^{-3}$ from $600 \mathrm{~m}$ to $900 \mathrm{~m}$

${ }_{403}$ and roughly constant potential density from 750 to $900 \mathrm{~m}$ (equivalent to $N \sim f$ ). This

${ }_{404}$ low stratified water is enclosed within an anticyclonic rotation. The deep isopycnals deformation is characteristics of Submesoscale Coherent Vortices (SCV) with a doming of

${ }_{410}$ is lower than the surroundings and remarkably homogeneous. As described before, the

${ }_{411}$ convective area had about the same $\theta / S_{P}$ characteristics as the SCV around mid-February

${ }_{412}$ in the Ligurian Sea. This would indicate the SCV was formed about 4.5 month prior to 413 its sampling during summer.

The SCV has a clear signature on heat, salt and oxygen distribution over the water 
${ }_{423}$ The SCV would impact the whole water column down to the bottom, likely due to its

${ }_{424}$ important barotropic rotation able to trap old deep waters during its formation. 
446 core. Ageostrophic cyclotrophic velocities reach $3.8 \mathrm{~cm} \mathrm{~s}^{-1}$ at a radial distance of $4.1 \mathrm{~km}$

${ }_{448}$ about $10 \%$ at the surface up to $\sim 45 \%$ around $700 \mathrm{~m}$ (see figure 5 -a, right panel). This

${ }_{449}$ confirms the important role of centrifugal effects in the balance of small-scale SCVs.

450 
${ }_{469}$ column stratification $\left(N^{2} \equiv-g \partial_{z} \sigma / \rho_{0}\right)$. The stratification generally decreases with depth:

${ }_{470}$ here $N \leq 5 f$ below $500 \mathrm{~m}$ (see figure 5 -c). This explains why subsurface eddies have a ${ }_{471}$ small radius compared to surface mesoscale eddies. The Burger number further quantifies ${ }_{472}$ the ratio of the deformation radius to the eddy radius: $B u \equiv[N H / f R]^{2}=\left[R_{d} / R\right]^{2}$. ${ }_{473}$ To compute the Burger number of the SCV, $H=1600 \mathrm{~m}$ is defined from the vertical ${ }_{474}$ extension of its geopotential anomaly at the center (i.e. larger than $20 \%$ of its maximum ${ }_{475}$ value at $\left.700 \mathrm{~m}\right)$ and $N=(4.0 \pm 0.4) f$ is the mean background stratification between 600 476 and $800 \mathrm{~m}$. This yields a Burger number of $1.14 \pm 0.22$, close to unity. In a low stratified 477 ocean, eddies have thus an unusual high aspect ratio $(R / H \sim N / f \in[1: 10])$. This is ${ }_{478}$ a particular feature shared by many SCVs observed around the world's oceans [D'Asaro, 479 1988; Timmermans et al., 2008; Bower et al., 2013; Pelland et al., 2013; Bosse et al., 2015], ${ }_{480}$ which can be theoretically explained in an idealized case [Carpenter and Timmermans, $\left.{ }_{481} 2012\right]$.

Effect on stratification and potential vorticity: The vertical stratification is significantly weakened inside the SCV almost to a factor of 2 with a mean value $2.4 f$ ${ }_{484}$ at $\sim 700 \mathrm{~m}$ (see figure 5 -c). Although there are few deep observations, the stratification ${ }_{485}$ increases close to the bottom, as observed at the base of deep anticyclonic SCVs [Bosse ${ }_{486}$ et al., 2016]. Combined with the strong negative vorticity, the PV is notably reduced up ${ }_{488}$ of stratification. The PV reaches values as low as $10^{-13} \mathrm{~m} \mathrm{~s}^{-1}$, which is one order of ${ }_{489}$ magnitude smaller than that of LIW SCVs formed by topographic interaction in the NW ${ }_{490}$ Mediterranean Sea [Bosse et al., 2015]. The PV conservation between an initial resting water parcel and the final rotating state enables to compute the initial stratification of 


\subsection{Dynamical barriers}

494

495 and extend to the eddy center.

By resolving the diffusion equation, a lateral isopycnic diffusion coefficient could be estimated for each tracer at different depths (see figure 6). Around to the velocity maximum between $550 \mathrm{~m}$ and $800 \mathrm{~m}$, the lateral gradient of temperature and salinity is too weak and no estimation is possible. Where it can be estimated, $K_{\rho}$ is $0.22 \pm 0.04 \mathrm{~m}^{2} \mathrm{~s}^{-1}$. The tracer distribution reaches background values at the radial distance of about $\sqrt{2} r_{0}$ $(=8.9 \mathrm{~km})$, where the relative vorticity becomes positive. This is also where the strain rate is maximum (see figure 5-b). The dynamical barriers of the SCV seem to start there

As explain in section 2.5, dissolved oxygen is the only tracer that provides $K_{\rho}$ estimates near the equilibrium depth of the SCV, where the horizontal vertical processes might be the smallest. There is consistent values among the different tracers, except below the core, where oxygen diffusivity seems to slightly diverge. This could the effect of unknown biological processes acting on the oxygen budget of the SCV. Indeed, Budéus et al. [2004] showed a stimulation of the bacterial activity in a deep convective SCVs observed in the Greenland Sea. However, this idea remains hard to verify here without dedicated measurements. Furthermore, the base of the SCV's core is a region of stronger stratification and where trapped near-inertial waves could enhance turbulence levels [Kunze et al., 1995; Sheen et al., 2015]. Diapycnal mixing could then increase there, pushing to the limit our simple 1D diffusion model. Again, with no turbulence measurements, we can unfortu- 
${ }_{513}$ nately not test this idea. Overall, all estimates agree on the order of magnitude of the ${ }_{514}$ diffusion coefficient of $0.2 \mathrm{~m}^{2} \mathrm{~s}^{-1}$.

Okubo [1971] reviewed estimates of the horizontal eddy diffusivity coefficient associated with oceanic turbulence and its scale dependency ranging $1-100 \mathrm{~m}^{2} \mathrm{~s}^{-1}$ for scales of 1$100 \mathrm{~km}$ (see also a nice and more recent review in introduction of Nencioli et al. [2013]). Here, we quantified the integral effect of unresolved small-sale processes on the erosion of the SCV's core. This has been previously done for Meddies in the Atlantic Ocean: Hebert et al. [1990] found a lateral eddy coefficient of $5 \mathrm{~m}^{2} \mathrm{~s}^{-1}$ associated with the decay of a $20 \mathrm{~km}$ radius Meddy and McWilliams [1985] $10 \mathrm{~m}^{2} \mathrm{~s}^{-1}$ for a typical $50 \mathrm{~km}$ radius ${ }_{522}$ Meddy. If Meddies and post-convective SCVs have a comparable lifetime $T$ of a few years,

${ }_{525}$ to involve different processes. While the rim of Meddies is a place of intense layering ${ }_{526}[$ Meunier et al., 2015] and their core is known to be subjected to double diffusive convection 
${ }_{536}$ post-convective $\mathrm{SCVs}$ of $5 \mathrm{~km}$ radius in a realistic high-resolution regional simulation. The

\subsection{Biogeochemical and biological impacts}

541

542

\subsubsection{Impact on nutrients concentration}

The SCV has an important impact on the nutrients distribution (see figure 8-a,b,c). Close to the surface, all nutriclines seem to be shallower by 20 to $50 \mathrm{~m}$ compared to the background environment leading to an enhancement of the nutrient availability at the base of the euphotic layer. Within the SCV core between $300 \mathrm{~m}$ and about $1500 \mathrm{~m}$ depth, the three main nutrients (Nitrate, Phosphate, Silicate) are significantly depleted with respective concentrations around $700 \mathrm{~m}$ of $6.9,0.34$ and $6.6 \mu \mathrm{mol} \mathrm{L}{ }^{-1}$. This is a decrease of 18, 13 and 18\% compared to background concentrations. As for other tracers, nutrients remain isolated from the surrounding environment because of the very limited lateral exchanges.

The formation process of the SCV can provide an explanation for these low values. Indeed, it results from the mixing of nutrients-poor surface waters with richer waters. Schematically, a $100 \mathrm{~m}$ thick surface layer with no nutrients being mixed with $700 \mathrm{~m}$ of nutrient-rich waters below would result in a nutrient concentration reduced by about 5 13\%. Following this argument, among the other type of post-convective SCVs described in Bosse et al. [2016], anticyclones with a deep core below $1000 \mathrm{~m}$ and cyclones of newly 
${ }^{557}$ formed deep waters would certainly have a less marked imprint on the nutrients, whereas

shallower Winter Intermediate Water SCVs would be even more nutrients-depleted.

\subsubsection{Impact on phytoplankton}

The radial distribution of chlorophyll-a measured by the glider is shown in figure 9a. Both $\left[\mathrm{Chl}_{a}\right]$ at the deep chlorophyll maximum (DCM) and integrated over the top $200 \mathrm{~m}$ reveal much higher concentrations inside the eddy with respectively $1.7 \mathrm{mg} \mathrm{m}^{-3}$ $(+113 \%)$ and $29 \mathrm{mg} \mathrm{m}^{-2}(+38 \%)$ (figure $\left.9-\mathrm{b}, \mathrm{c}\right)$. The eddy dynamics seems thus to favor phytoplankton growth, much likely as a result of the isopycnals doming characteristic of cyclonic and "Mode Water" anticyclones [McGillicuddy et al., 2007; Nencioli et al., 2008].

The isopycnals doming is quite marked at about $100 \mathrm{~m}$ deep, while it is dumped closer to the surface due to summer stratification. This can explain why nutriclines are displaced of about 20-50 m increasing the nutrients availability, whereas the DCM only moves by less than $10 \mathrm{~m}$ (figure 9-d).

Regarding the phytoplankton size group, HPLC measurements show a clear predominance of nanophytoplankton inside the eddy with a concentration of $0.86 \mathrm{mg} \mathrm{m}^{-3}$, about twice the median value of $0.44 \mathrm{mg} \mathrm{m}^{-3}$ observed in the Ligurian Sea (see figure $9-\mathrm{e}$ ). This 3 is one of the most abundant station for nanophytoplankton, which represents almost $80 \%$ 54 of the total chlorophyll-a. Note that the glider fluorometer calibrated with satellite images 75 is in good agreement with the total chlorophyll-a concentration of $1.1 \mathrm{mg} \mathrm{m}^{-3}$ measured by HPLC. 


\section{Discussion}

\subsection{Fate and decline of post-convective SCVs}




\subsection{Primary production and carbon sequestration}




\section{Summary and Conclusion}


711 the context of climate change.

\section{Appendix A: The heat equation in cylindrical coordinate}

Lets consider the evolution of a tracer $T$ whose concentration is initially constant $T=T_{0}$ and confined within a long cylinder of radius $R$. In this case, the heat equation goes by in its cylindrical form:

$$
\frac{\partial T}{\partial t}=K \frac{1}{r} \frac{\partial}{\partial r}\left(r \frac{\partial T}{\partial r}\right)
$$

The desired solution of this equation owes to verify: (1) $\partial_{r} T=0$ at $r=0$ as imposed

Each side of the equation being a function of an independent variable $(r$ and $t)$, it has thus to be constant. Furthermore, this constant must be negative to prevent $\beta$ from exponentially diverging in time. Lets call it $-\lambda^{2}$, we then have:

$$
r^{2} \frac{d^{2} \alpha}{d r^{2}}+r \frac{d \alpha}{d r}+r^{2} \lambda^{2}=0 \quad \text { and } \quad \frac{d \beta}{d t}+K \lambda^{2} \beta=0
$$

${ }_{717}$ The general solution for $\beta$ is simply: $\beta(t)=\beta_{0} e^{-\lambda^{2} D t}$ where $\beta_{0}$ is a constant. 
Since $T(r=L, t)=T_{\infty}$, this requires $J_{0}(\lambda L)=0$. Knowing the zeros of the Bessel function $J_{0}$, one can thus define $\lambda_{n}$ the eigenvalues of the problem and the particular solutions for the problem: $T_{n}(r, t)=T_{\infty}+A_{n} J_{0}\left(\lambda_{n} r\right) e^{-\lambda_{n}^{2} D t}$ with $A_{n}=\alpha_{0}^{n} \beta_{0}$. The general solution then writes:

$$
T(r, t)=T_{\infty}+\sum_{n=1}^{\infty} A_{n} J_{0}\left(\lambda_{n} r\right) e^{-\lambda_{n}^{2} K t}
$$

To infer the coefficients $A_{n}$, one can project the initial condition $\left(T(r, t=0)-T_{\infty}=\right.$ $\left.T_{0}-T_{\infty}\right)$ onto a particular eigenfunction $J_{0}\left(\lambda_{m} r\right)$ and use the orthogonality of each eigenfunction $\left(\int_{[0, L]} r J_{0}\left(\lambda_{m} r\right) J_{0}\left(\lambda_{n} r\right) d r=0\right.$ if $n \neq m,=1$ otherwise):

$$
\int_{0}^{L} r J_{0}\left(\lambda_{m} r\right)\left(T_{0}-T_{\infty}\right) d r=\sum_{n=1}^{\infty} \int_{0}^{L} r A_{n} J_{0}\left(\lambda_{m} r\right) J_{0}\left(\lambda_{n} r\right) d r=A_{m} \int_{0}^{L} r J_{0}\left(\lambda_{m} r\right)^{2} d r(\mathrm{~A} 5)
$$

then knowing that: $\int_{[0, L]} r J_{0}\left(\lambda_{m} r\right) d r=L J_{1}\left(\lambda_{m} L\right) / \lambda_{m}$ and $\int_{[0, L]} r J_{0}^{2}\left(\lambda_{m} r\right) d r=$ $L^{2}\left[J_{0}^{2}\left(\lambda_{m} L\right)+J_{1}^{2}\left(\lambda_{m} L\right)\right] / 2=L^{2} J_{1}^{2}\left(\lambda_{m} L\right) / 2$, one can explicit the different coefficient $A_{m}$ and write the final solution of our problem:

$$
T(r, t)=T_{\infty}+\frac{2\left(T_{0}-T_{\infty}\right)}{L} \sum_{n=1}^{\infty} \frac{J_{0}\left(\lambda_{n} r\right)}{\lambda_{n} J_{1}\left(\lambda_{n} L\right)} e^{-\lambda_{n}^{2} K t}
$$

\section{Acknowledgments.}

The hydrographical data were collected and made freely available by the Coriolis project and programmes that contribute to it (http://www.coriolis.eu.org). The cruise data is provided in the reference section along with the associated doi. Vincent Tailliandier is thanked for the calibration of shipborne CTD and providing feedback on the manuscript. We would like to acknowledge the staff of the French National Pool of Gliders of DT-INSU 
${ }_{727}$ (CNRS/Ifremer) for the sustained gliders deployments carried out in the framework of ${ }_{728}$ MOOSE, as well as the intensive deployments during this 2012-2013 DEWEX experi${ }_{729}$ ment. Captains and crew of $\mathrm{R} / \mathrm{V}$ Le Tethys II (CNRS/INSU) and Le Suroit (Ifremer) ${ }_{730}$ as well as all scientists, engineers and technicians who participated to the MOOSE-GE ${ }_{731}$ and DEWEX different cruises and autonomous platforms deployments are also warmly thanked. Support was provided by the French the French "Chantier Méditrranée" MISTRALS program (HyMeX and MERMeX components) and the French MOOSE long-term ${ }_{734}$ observatory (SOERE/AllEnvi-SNO/INSU), as well as by th EU projects FP7 GROOM ${ }_{735}$ (Grant Agreement No. 284321), FP7 PERSEUS (Grant Agreement No. 287600) and FP7 ${ }_{736}$ JERICO (Grant Agreement No. 262584) and the COST Action ES0904 "EGO" (Every${ }_{737}$ one's Gliding Observatories). A. Bosse was funded by a French government scholarship.

\section{References}

Aminot, A., and R. Kérouel, Dosage automatique des nutriments dans les eaux marines, Ed. Ifremer, 2007.

Armi, L., D. Hebert, N. Oakey, J. F. Price, P. L. Richardson, H. T. Rossby, and B. Ruddick, Two Years in the Life of a Mediterranean Salt Lens, Journal of Physical Oceanography, 19, 354-370, 1989.

Béthoux, J.-P., B. Gentili, J. Raunet, and D. Tailliez, Warming trend in the western Mediterranean deep water, Nature, 347, 660-662, 1990.

Bosse, A., Circulation générale et couplage physique-biogéochimie à (sous-)mésoéchelle en Méditerranée Nord-occidentale à partir de données in situ, Ph.D. thesis, Université Pierre et Marie Curie, Paris, 2015. 
Bosse, A., P. Testor, L. Mortier, L. Prieur, V. Taillandier, F. D'Ortenzio, and L. Coppola, Spreading of Levantine Intermediate Waters by submesoscale coherent vortices in the northwestern Mediterranean Sea as observed with gliders, Journal of Geophysical Research: Oceans, 120, 1599-1622, 2015.

Bosse, A., et al., Scales and dynamics of submesoscale coherent vortices formed by deep convection in the northwestern mediterranean sea, Journal of Geophysical Research: Oceans, 121, 7716-7742, 2016.

Bouffard, J., A. Pascual, S. Ruiz, Y. Faugère, and J. Tintoré, Coastal and mesoscale dynamics characterization using altimetry and gliders: A case study in the Balearic Sea, Journal of Geophysical Research: Oceans, 115, 1-17, 2010.

Bouffard, J., L. Renault, S. Ruiz, A. Pascual, C. Dufau, and J. Tintoré, Sub-surface small-scale eddy dynamics from multi-sensor observations and modeling, Progress in Oceanography, 106, 62-79, 2012.

Bower, A. S., R. M. Hendry, D. E. Amrhein, and J. M. Lilly, Direct observations of formation and propagation of subpolar eddies into the subtropical North Atlantic, Deep Sea Res. II, 85, 15-41, 2013.

Bretherton, F. P., R. E. Davis, and C. B. Fandry, A technique for objective analysis and design of oceanographic experiments applied to MODE-73, Deep Sea Research and Oceanographic Abstracts, 23, 559-582, 1976.

Budéus, G., B. Cisewski, S. Ronski, D. Dietrich, and M. Weitere, Structure and effects of a long lived vortex in the Greenland Sea, Geophysical Research Letters, 31, 1-5, 2004. Carpenter, J. R., and M.-L. Timmermans, Deep mesoscale eddies in the Canada Basin, Arctic Ocean, Geophysical Research Letters, 39, 1-6, 2012. 
Ciani, D., X. Carton, I. Bashmachnikov, B. Chapron, and X. Perrot, Influence of Deep Vortices on the Ocean Surface, Discontinuity, Nonlinearity, and Complexity, 4, 281$311,2015$.

Claustre, H., The trophic status of various oceanic provinces as revealed by phytoplankton pigment signatures, Limnology and Oceanography, 39, 1206-1210, 1994.

Cotroneo, Y., G. Aulicino, S. Ruiz, A. Pascual, G. Budillon, G. Fusco, and J. Tintoré, Glider and satellite high resolution monitoring of a mesoscale eddy in the algerian basin: Effects on the mixed layer depth and biochemistry, Journal of Marine Systems, 2015.

Cuypers, Y., P. Bouruet-Aubertot, C. Marec, and J.-L. Fuda, Characterization of turbulence from a fine-scale parameterization and microstructure measurements in the Mediterranean Sea during the BOUM experiment, Biogeosciences, 9, 3131-3149, 2012.

Damien, P., A. Bosse, P. Testor, P. Marsaleix, and C. Estournel, Modelling post convective submesoscale coherent vortices in the mediterranean sea, Journal of Geophysical Research: Oceans, in revision, this issue.

D'Asaro, E., Observations of small eddies in the Beaufort Sea, Journal of Geophysical Research, 93, 6669-6684, 1988.

DOE, Handbook of Methods for the Analysis of the Various Parameters of the Carbon Dioxide System in Sea Water; version 2, A. G. Dickson and C. Goyet, eds., ORNL/CDIAC-74, 1994.

Durrieu de Madron, X., et al., Marine ecosystems' responses to climatic and anthropogenic forcings in the Mediterranean, Progress in Oceanography, 91, 97-166, 2011.

Durrieu de Madron, X., et al., Deep sediment resuspension and thick nepheloid layer generation by open-ocean convection, Journal of Geophysical Research: Oceans, pp. 
n/a-n/a, 2017.

Elliott, B. A., and T. B. Sanford, The Subthermocline Lens D1. Part II: Kinematics and Dynamics, Journal of Physical Oceanography, 16, 549-561, 1986.

Ertel, H., Ein neuer hydrodynamischer wirbelsatz, Meteorol. Z., 59, 277-281, 1942.

Estournel, C., et al., HyMeX-SOP2, the field campaign dedicated to dense water formation in the north-western Mediterranean, Oceanography, accepted.

Fan, X., U. Send, P. Testor, J. Karstensen, P. Lherminier, and G. Drive, Observations of Irminger Sea Anticyclonic Eddies, Journal of Physical Oceanography, 43, 805-823, 2013.

Frajka-Williams, E., P. B. Rhines, and C. C. Eriksen, Physical controls and mesoscale variability in the Labrador Sea spring phytoplankton bloom observed by Seaglider, Deep Sea Research Part I: Oceanographic Research Papers, 56, 2144-2161, 2009.

Garau, B., S. Ruiz, W. G. Zhang, A. Pascual, E. E. Heslop, J. Kerfoot, and J. Tintoré, Thermal Lag Correction on Slocum CTD Glider Data, Journal of Atmospheric and Oceanic Technology, 28, 1065-1071, 2011.

Gascard, J.-C., Mediterranean deep water formation baroclinic instability and oceanic eddies, Oceanologica Acta, 1, 315-330, 1978.

Gascard, J.-c., A. J. Watson, M.-J. Messias, K. A. Olsson, T. Johannessen, and K. Simonsen, Long-lived vortices as a mode of deep ventilation in the Greenland Sea, Nature, $416,525-527,2002$.

Gasparini, G. P., A. Ortona, G. Budillon, M. Astraldi, and E. Sansone, The effect of the Eastern Mediterranean Transient on the hydrographic characteristics in the Strait of Sicily and in the Tyrrhenian Sea, Deep-Sea Research Part I: Oceanographic Research 
Papers, 52, 915-935, 2005.

Hebert, D., N. Oakey, and B. Ruddick, Evolution of a Mediterranean Salt Lens: Scalar Properties, Journal of Physical Oceanography, 20, 1468-1483, 1990.

Houpert, L., et al., Observations of open-ocean deep convection in the northwestern mediterranean sea: Seasonal and interannual variability of mixing and deep water masses for the 20072013 period, Journal of Geophysical Research: Oceans, pp. n/a$\mathrm{n} / \mathrm{a}, 2016$.

Hua, B. L., C. Ménesguen, S. Le Gentil, R. Schopp, B. Marsset, and H. Aiki, Layering and turbulence surrounding an anticyclonic oceanic vortex: in situ observations and quasi-geostrophic numerical simulations, Journal of Fluid Mechanics, 731, 418-442, 2013.

Janzen, C., D. Murphy, and N. Larson, Getting more mileage out of dissolved oxygen sensors in long-term moored applications, in OCEANS 2007, pp. 1-5, 2007.

Jones, H., and J. Marshall, Restratification after Deep Convection, Journal of Physical Oceanography, 27, 2276-2287, 1997.

Joyce, T. M., L. N. Thomas, and F. Bahr, Wintertime observations of Subtropical Mode Water formation within the Gulf Stream, Geophysical Research Letters, 36, 1-5, 2009.

Juza, M., L. Renault, S. Ruiz, and J. Tintoré, Origin and pathways of Winter Intermediate Water in the Northwestern Mediterranean Sea using, J. Geophys. Res., 2013.

Karstensen, J., et al., Upwelling and isolation in oxygen-depleted anticyclonic modewater eddies and implications for nitrate cycling, Biogeosciences Discussions, pp. 1-25, in review, 2016. 
Kirkwood, D. S., Stability of solutions of nutrient salts during storage, Marine Chemistry, 38, 151-164, 1992.

Klemas, V., and X. H. Yan, Subsurface and deeper ocean remote sensing from satellites: An overview and new results, 122, 1-9, 2014.

Kloosterziel, R. C., G. F. Carnevale, and P. Orlandi, Inertial instability in rotating and stratified fluids: barotropic vortices, Journal of Fluid Mechanics, 583, 379-412, 2007.

Krahmann, G., and F. Schott, Longterm increases in western Mediterranean salinities and temperatures: Anthropogenic and climatic sources, Geophysical Research Letters, 25, 4209, 1998.

Kunze, E., R. W. Schmitt, and J. M. Toole, The energy balance in a warm-core ring's near-inertial critical layer, Journal of Physical Oceanography, 25, 942-957, 1995.

Lachkar, Z., S. Smith, M. Levy, and O. Pauluis, Eddies reduce denitrification and compress habitats in the Arabian Sea, Geophysical Research Letters, 2016.

Lavigne, H., F. D’Ortenzio, H. Claustre, and A. Poteau, Towards a merged satellite and in situ fluorescence ocean chlorophyll product, Biogeosciences, 9, 2111-2125, 2012.

Le Traon, P.-Y., IOpt, Journal of Geophysical Research, 95, 543-547, 1990.

Leaman, K. D., and F. a. Schott, Hydrographic Structure of the Convection Regime in the Gulf of Lions: Winter 1987, Journal of Physical Oceanography, 21, 575-598, 1991.

Legg, S., and J. C. Marshall, A Heton Model of the Spreading Phase of Open-Ocean Deep Convection, Journal of Physical Oceanography, 23, 1040-1056, 1993.

Legg, S., J. McWilliams, and J. Gao, Localization of Deep Ocean Convection by a Mesoscale Eddy, Journal of Physical Oceanography, 28, 944-970, 1998. 
Lherminier, P., J.-C. Gascard, and D. Quadfasel, The Greenland Sea in Water 1993 and 1994: preconditioning for deep convection, Deep Sea Research Part II: Topical Studies in Oceanography, 46, 1199-1235, 1999.

Lilly, J. M., and P. B. Rhines, Coherent Eddies in the Labrador Sea Observed from a Mooring, Journal of Physical Oceanography, 32, 585-598, 2002.

Löscher, C. R., et al., Hidden biosphere in an oxygen-deficient Atlantic open-ocean eddy: Future implications of ocean deoxygenation on primary production in the eastern tropical North Atlantic, Biogeosciences, 12, 7482-7482, 2015.

Margirier, F., A. Bosse, P. Testor, B. L'Hévéder, L. Mortier, and D. Smeed, Characterization of convective plumes associated with oceanic deep convection in the Northwestern Mediterranean from high resolution in-situ data collected by gliders, Journal of Geophysical Research, submitted, this issue.

Marshall, J., and F. Schott, Open-ocean convection: Observations, theory, and models, Reviews of Geophysics, 37, 1-64, 1999.

Martin, J. P., C. M. Lee, C. C. Eriksen, C. Ladd, and N. B. Kachel, Glider observations of kinematics in a Gulf of Alaska eddy, Journal of Geophysical Research, 114, 1-19, 2009.

Mayot, N., F. d'Ortenzio, V. Taillandier, L. Prieur, O. P. de Fommervault, H. Claustre, A. Bosse, P. Testor, and P. Conan, Impacts of the deep convection on the phytoplankton blooms in temperate seas: a multiplatform approach over a complete annual cycle (20122013 DEWEX experiment), Journal of Geophysical Research, in revision, this issue.

Mayot, N., F. d'Ortenzio, J. Uitz, B. Gentili, J. Ras, V. Vellucci, M. Golbol, D. Antoine, and H. Claustre, Influence of the phytoplankton community structure on the spring 
and annual primary production in the North-Western Mediterranean Sea, Journal of Geophysical Research, submitted, this issue.

McGillicuddy, D. J., et al., Eddy/wind interactions stimulate extraordinary mid-ocean plankton blooms., Science, 316, 1021-6, 2007.

McWilliams, J. C., Submesoscale, coherent vortices in the ocean, Reviews of Geophysics, 23, 165, 1985.

McWilliams, J. C., Vortex Generation Through Balanced Adjustment, Journal of Physical Oceanography, 18, 1178-1192, 1988.

McWilliams, J. C., Submesoscale currents in the ocean, Proceedings of the Royal Society of London A: Mathematical, Physical and Engineering Sciences, 472, 2016.

MEDOC-Group, T., Observation of Formation of Deep Water in the Mediterranean Sea, 1969, Nature, 225, 1037-1040, 1970.

Meunier, T., C. Ménesguen, R. Schopp, and S. Le Gentil, Tracer Stirring around a Meddy: The Formation of Layering, Journal of Physical Oceanography, 45, 407-423, 2015.

Millot, C., The circulation of the Levantine Intermediate Water in the Algerian Basin, Journal of Geophysical Research, 92, 8265, 1987.

Millot, C., Circulation in the Western Mediterranean Sea, J. Mar. Syst., 20, 423-442, 1999.

Morel, A., Light and marine photosynthesis: a spectral model with geochemical and climatological implications, Progress in Oceanography, 1991, 263 - 306, 1991.

Morel, A., and J.-F. Berthon, Surface pigments, algal biomass profiles, and potential production of the euphotic layer: Relationships reinvestigated in view of remote-sensing applications, Limnology and Oceanography, 34, 1545-1562, 1989. 
Provenzale, A., Transport by coherent barotropic vortices, Annual Review of Fluid Mechanics, 31, 55-93, 1999.

Ras, J., H. Claustre, and J. Uitz, Spatial variability of phytoplankton pigment distributions in the subtropical south pacific ocean: comparison between in situ and predicted data, Biogeosciences, 5, 353-369, 2008.

Rhines, P. B., and W. R. Young, How rapidly is a passive scalar mixed within closed streamlines?, Journal of Fluid Mechanics, 133, 133-145, 1983.

Schott, F., and K. D. Leaman, Observations with Moored Acoustic Doppler Current Profilers in the Convection Regime in the Golfe du Lion, 1991.

Schroeder, K., J. Chiggiato, H. L. Bryden, M. Borghini, and S. Ben Ismail, Abrupt climate shift in the Western Mediterranean Sea, Scientific Reports, 6, 23,009, 2016.

Send, U., J. Font, and C. Mertens, Recent observation indicates convection's role in deep water circulation, Eos, 77, 61-65, 1996.

Sheen, K. L., J. A. Brearley, A. C. Naveira Garabato, D. A. Smeed, L. S. Laurent, M. P. Meredith, A. M. Thurnherr, and S. N. Waterman, Modification of turbulent dissipation rates by a deep southern ocean eddy, Geophysical Research Letters, 42, 3450-3457, 2015, 2015GL063216.

Somot, S., F. Sevault, and M. Déqué, Transient climate change scenario simulation of the Mediterranean Sea for the twenty-first century using a high-resolution ocean circulation model, Climate Dynamics, 27, 851-879, 2006.

Testor, P., DEWEX-MERMEX 2013 LEG1 cruise, RV Le Suroît, Tech. rep., 2013.

Testor, P., and J.-C. Gascard, Large-Scale Spreading of Deep Waters in the Western Mediterranean Sea by Submesoscale Coherent Eddies, Journal of Physical Oceanogra- 

phy, 33, 75-87, 2003.

Testor, P., and J.-C. C. Gascard, Post-convection spreading phase in the Northwestern Mediterranean Sea, Deep Sea Research Part I, 53, 869-893, 2006.

Testor, P., L. Coppola, and L. Mortier, MOOSE-GE 2013 cruise, RV Téthys II, Tech. rep., 2013.

Testor, P., et al., Gliders as a component of future observing systems, Proceedings of OceanObs'09: Sustained Ocean Observations and Information for Society (Vol. 2), Venice, Italy, 21-25 September 2009, J. Hall, D.E. Harrison E3 D. Stammer Eds., 2010. Testor, P., et al., Observation of deep convection in the northwestern Mediterranean sea during winter 2012-2013, Journal of Geophysical Research: Oceans, in revision, this issue.

Thierry, V., and H. Bittig, Argo quality control manual for dissolved oxygen concentration, Argo-BGC Team report, Tech. rep., 2016.

Thomsen, S., T. Kanzow, G. Krahmann, R. J. Greatbatch, M. Dengler, and G. Lavik, The formation of a subsurface anticyclonic eddy in the peru-chile undercurrent and its impact on the near-coastal salinity, oxygen, and nutrient distributions, Journal of Geophysical Research: Oceans, 121, 476-501, 2016.

Timmermans, M.-L., J. Toole, R. Krishfield, and P. Winsor, Ice-Tethered Profiler observations of the double-diffusive staircase in the Canada Basin thermocline, Journal of Geophysical Research, 113, 2008.

Uitz, J., H. Claustre, A. Morel, and S. B. Hooker, Vertical distribution of phytoplankton communities in open ocean: An assessment based on surface chlorophyll, Journal of Geophysical Research: Oceans, 111, n/a-n/a, 2006, c08005. 
Uitz, J. U., Y. Huot, F. Bruyant, M. Babin, and H. Claustre, Relating phytoplankton photophysiological properties to community structure on large scales, Limnology and Oceanography, 53, 614-630, 2008.

Vargas-Yáñez, M., et al., Extreme Western Intermediate Water formation in winter 2010, Journal of Marine Systems, 105-108, 52-59, 2012.

Vidussi, F., H. Claustre, B. B. Manca, A. Luchetta, and J.-C. Marty, Phytoplankton pigment distribution in relation to upper thermocline circulation in the eastern mediterranean sea during winter, Journal of Geophysical Research: Oceans, 106, 19,939-19,956, 2001.

Visbeck, M., Deep velocity profiling using lowered acoustic doppler current profilers: Bottom track and inverse solutions, Journal of Atmospheric and Oceanic Technology, 19, 794-807, 2002.

Visbeck, M., J. Marshall, and H. Jones, Dynamics of Isolated Convective Regions in the Ocean, Journal of Physical Oceanography, 1996.

Waite, A. M., L. Stemmann, L. Guidi, P. H. R. Calil, A. M. Hogg, M. Feng, P. A. Thompson, M. Picheral, and G. Gorsky, To the Deep Ocean in Mesoscale Eddies, Geophysical Research Letters, 43, 9791--9800, 2016.

Xing, X., H. Claustre, S. Blain, F. d'Ortenzio, D. Antoine, J. Ras, and C. Guinet, for in vivo chlorophyll fluorescence acquired by autonomous platforms: A case study with instrumented elephant seals in the Kerguelen region (Southern Ocean, Limnol. Oceanogr., pp. 483-495, 2012. 
Figure 1. (a) CTD casts carried out in the Ligurian Sea during the DEWEX winter cruise in February 2013. Stations were distinguished according to the observed mixed layer depth. The right panel shows the trajectory of glider during the concomitant glider mission MOOSE T00-23. Dots are colored according to the mixed layer mean potential temperature observed between February 11 and 17 with the same color scale as in (c). Depth-average currents estimated by the glider are also shown in dark gray. (b) Full-depth shipborne CTD casts during the winter with dark gray profiles corresponding to deeply mixed profiles. The blue profile is a deeply mixed profile carried out in the Ligurian Sea. The SCV core characteristics is indicated by the thick dashed blue line. (c) Glider section along three consecutive Nice-Calvi sections. From top to botom: potential temperature, practical salinity, chlorophyll-a fluorescence and dissolved oxygen. Black contours are isopycnals and the white line represent the mixed layer depth. On top of these panels, dots show the high-resolution sampling of the glider.

Figure 2. Same as figure 1 but for the MOOSE-GE 2013 summer cruise and the MOOSE T00-25 glider mission carried out in June-July 2013. In (a), the colored dots along the glider trajectory represents the dissolved oxygen concentration with the same scale as in $(c)$. Note that total carbon was measured at the same stations as phytoplankton pigments. In panel (b), the light gray profiles correspond to those carried out in the Ligurian Sea (defined by the black box drawn in $(a)$ ), the black profile is the average of all the gray profiles. The blue profile was carried out within the core of a deep eddy that was further sampled by a glider shortly afterward. 
Figure 3. Glider sampling of the SCV. (a) Optimal interpolation of the potential temperature at $400 \mathrm{~m}$ and $900 \mathrm{~m}$ in the eddy centered rotating coordinate framework (i.e. all profiles and depth-average currents from the glider have been rotated around the eddy center according to radial orbital depth-average currents and their observation date). Radial distribution of (b) potential temperature at $900 \mathrm{~m}$ and (c) orbital depth-average currents estimated by the glider. The fitted gaussian distribution of orbital velocities is also drawn $\left(r_{0}=6.3 \mathrm{~km}\right.$ and $\left.v_{0}=12.2 \mathrm{~cm} \mathrm{~s}^{-1}\right)$. The geostrophic component of orbital depth-average currents deduced following Bosse et al. [2016] is also shown by the light black line. Note that outliers plotted in gray have been excluded prior to the curve fitting. Histograms representing the number of observations in $1 \mathrm{~km}$ bins are also shown in upper panels.

Figure 4. Hydrography of the SCV. Radial distribution of (a) potential temperature, (b) practical salinity and (c) dissolved oxygen (DO). Black contours represent potential density in $\mathrm{kg} \mathrm{m}^{-3}$. All those fields result from the optimal interpolation constrained by the intense glider survey of the first $1000 \mathrm{~m}$ depth. Below that depth, area away from the full-depth profiles inside and outside the SCV core have been shaded. Those profiles are also shown as scatter points on top of the analyzed fields. Note that a radial symmetry has been applied for aesthetic and clarity purposes. 
Figure 5. Dynamical diagnostics of the SCV. (a) Radial distribution of cyclogeostrophic velocities $v_{c}$. The peak orbital velocity is indicated (at $r=6.1 \mathrm{~km}$ and $700 \mathrm{~m}$ depth). Gray contours represent the only cyclostrophic component of orbital velocities. The red line follows peak velocities over depth. The right panel quantifies the percentage ageostrophy over depth: $\left(1-\max _{z}\left|v_{g}\right| / \max _{z}\left|v_{c}\right|\right) \times 100$. (b) Relative vorticity normalized by $f$. The blue line follows the change of sign of the vorticity. The minimum and maximum values are also indicated. The gray lines are contours of strain normalized by $f$. (c) Radial distribution of the stratification anomaly relative to the background. The gray contours show the smoothed density field used to compute the geostrophic shear and stratification. (d) Radial distribution of the potential vorticity anomaly relative to the background. The red and blue lines are redrawn on this panel. For (c) and (d), the background is defined as the averaged field between 15 and $20 \mathrm{~km}$ (see black lines in right panels). In contrast, profile representative of the SCV core is taken as the averaged field between 0 and $5 \mathrm{~km}$ (see blue lines in right panels). Note that we have shaded the area below $1000 \mathrm{~m}$ depth, as dynamical diagnostics are only constrained by two full-depth CTD casts and a subsequent optimal interpolation.

Figure 6. Horizontal diffusion of oxygen, heat and salt at the rim of the SCV. (a) The gray dots are the individual observations from the glider of dissolved oxygen (left), potential temperature (middle) and salinity (right) at different depths $(450 \mathrm{~m}, 700 \mathrm{~m}$ and $950 \mathrm{~m}$, from the top to the bottom). The black line is the average in $1 \mathrm{~km}$ bins with error bar showing the standard deviation in each bin. The light colored line represents the tracer distribution at $t=0$ and the thick line after 4.5 months of diffusion with the diffusion coefficient optimized to fit the observed data. (b) Distribution of diffusion coefficient as a function of depth for the different tracers. 
Figure 7. Salinity-Oxygen diagram. The gray lines correspond to background profiles carried out in the Ligurian Sea and the black line is their average. The blue line is the particular profile within the SCV.

Figure 8. Concentrations of the three main nutrients and carbon measured during the MOOSEGE 2013 cruise: (a) nitrate, (b) phosphate, (c) silicate ions and (d) total carbon. The blue dots show the concentration within the SCV core, while black dots are from the other stations carried in the eastern part of the basin (i.e. longitude $>6^{\circ} \mathrm{E}$, see the corresponding stations in figure 2-a). The gray shaded area represents the standard deviation of the data.

Figure 9. (a) Bin-averaged section across the eddy of the chlorophyll-a concentration measured by the glider. Black contours show the isopycnals. Note that a radial symmetry has been applied for aesthetic and clarity purposes. Radial distribution of: (b) the chlorophyll-a concentration measured at the deep chlorophyll maximum; (c) the integrated chlorophyll-a concentration over the top $200 \mathrm{~m}$; and (d) the depth of this deep chlorophyll maximum. (e) Chlorophyll-a concentration of three phytoplankton size classes. (f) Primary production associated with each size group. The box plots were constructed using all measurements carried out during the MOOSE-GE 2013 cruise in the eastern part of the basin (i.e. longitude $>6^{\circ} \mathrm{E}$, see the corresponding stations in figure 2-a). The red mark is the median, the box limits the $25^{\text {th }}$ and $75^{\text {th }}$ percentile and the whiskers show the extension of the dataset. The particular SCV core station is highlighted in blue, as well as the two closest HPLC stations carried out in the Ligurian Sea (Lig1 and Lig2). 
Figure 10. Remotely sensed chlorophyll-a concentration at the ocean surface measured by MODIS Aqua scatterometer in June 2013 in the Ligurian Sea. The black dots are the eddy center deduced by in situ observations. The white dot is the interpolated eddy center position at the moment the images were taken. A circle of is $12.6 \mathrm{~km}$ radius $\left(=2 r_{0}\right)$ is drawn to show the eddy outer extension. Note that these are the only good images found from June 13 to July 7. 
'Figure 1'. 
(a)

DEWEX leg1, Feb 03 - Feb 21, 2013
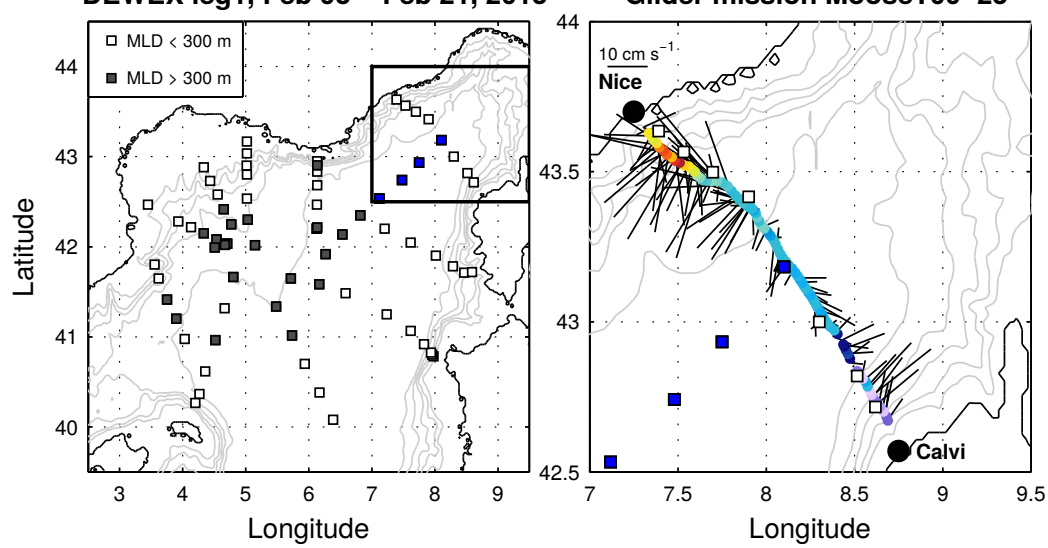

(b)

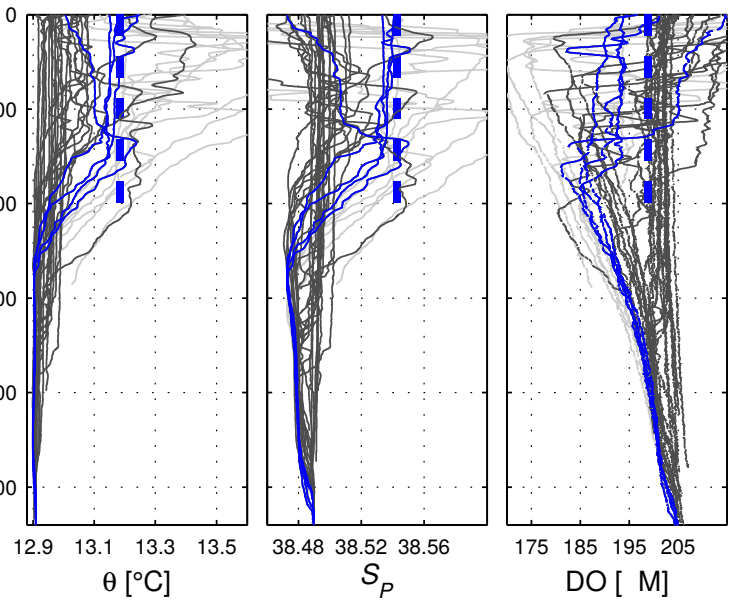

(c)

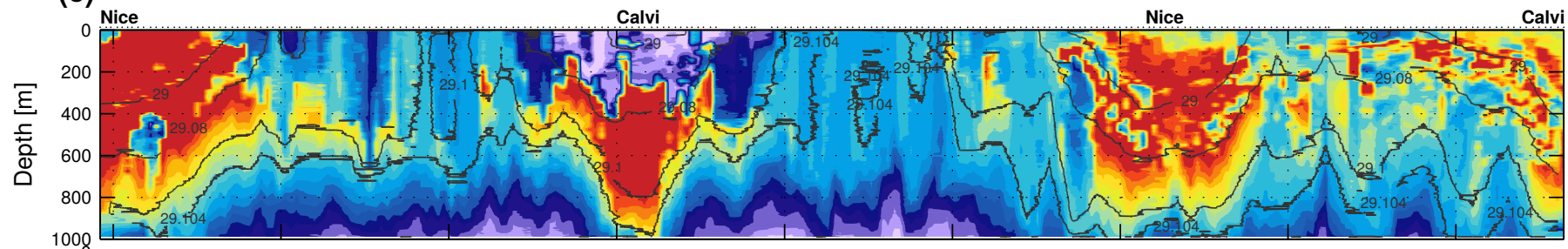

E

E
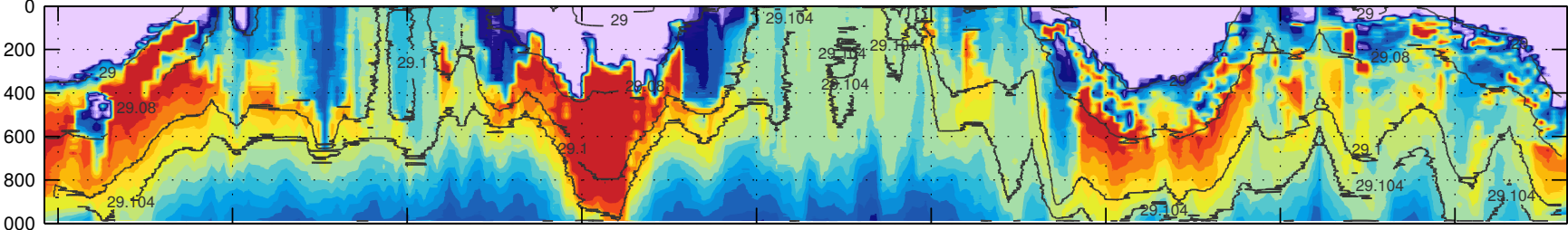

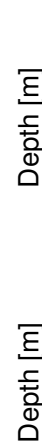

1000
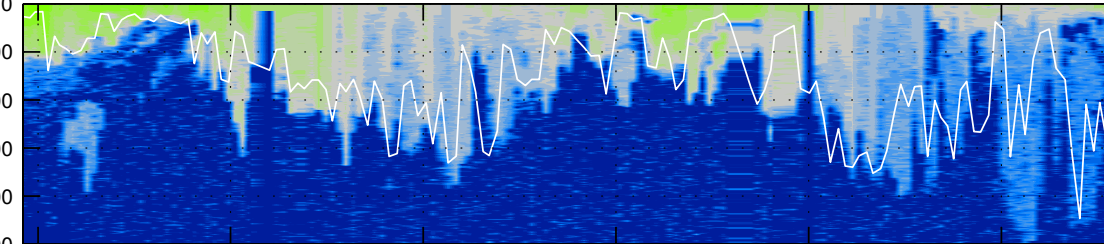

L
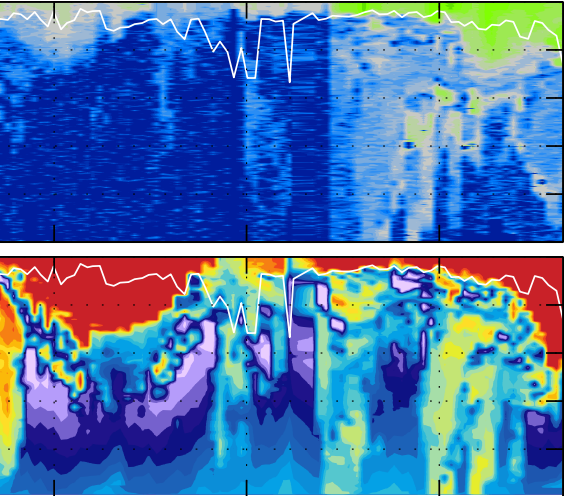

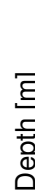

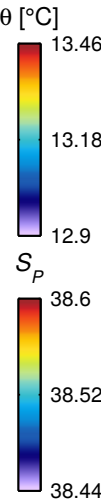

$\mathrm{HL}\left[\mathrm{mg} \mathrm{m}^{-3}\right.$

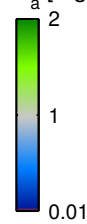

DO $[\mu \mathrm{M}]$

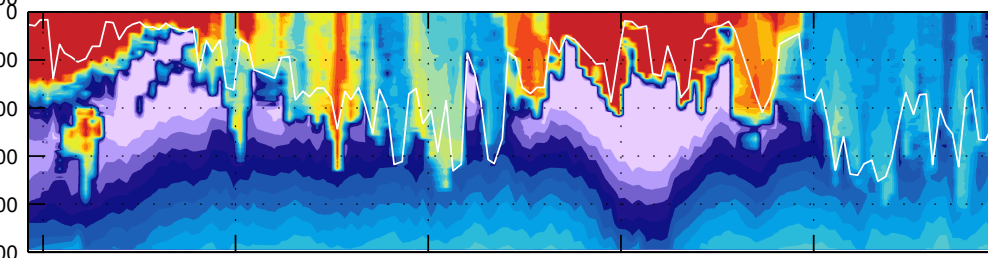

Feb 05

Feb 07

Feb 09

Feb 11

Feb 13

Date

Feb 15
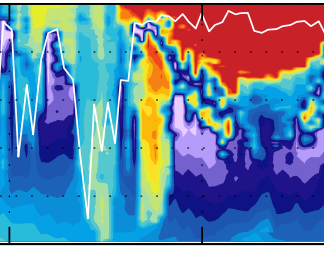

Feb 17

Feb 19

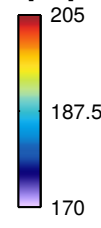


'Figure 2'. 
Figure 3. 
$\theta\left[{ }^{\circ} \mathrm{C}\right]$

(b)

\begin{tabular}{rrrrrr}
12.9 & 13 & 13.1 & 13.2 & 13.3 & 13.4 \\
\hline
\end{tabular}

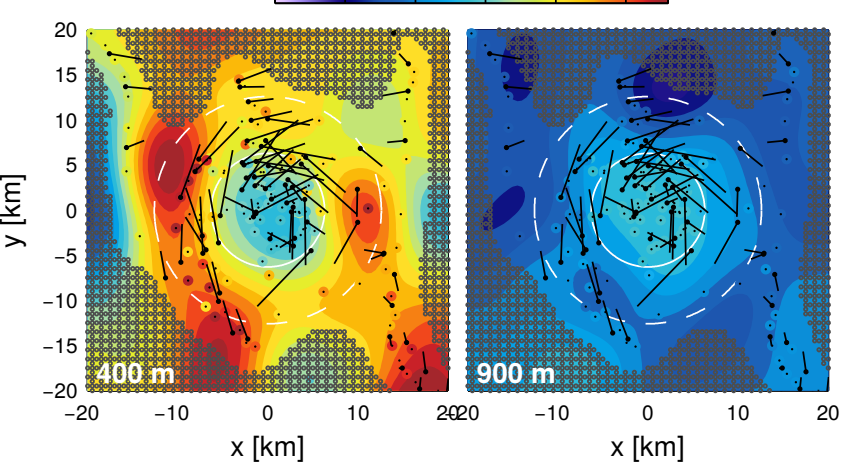

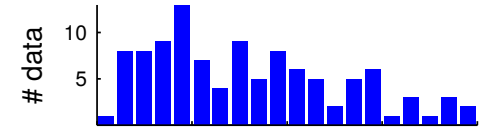

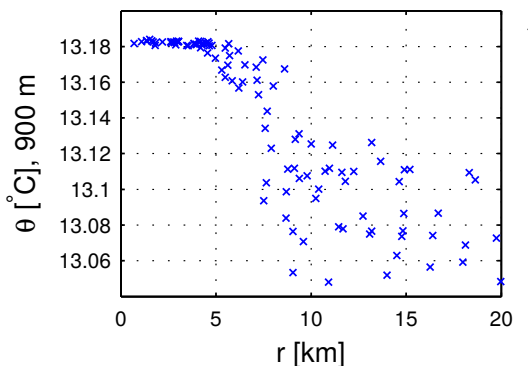

(c)
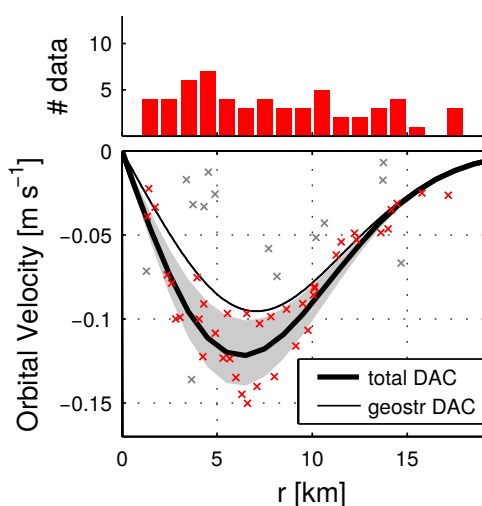

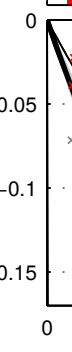

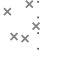

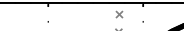

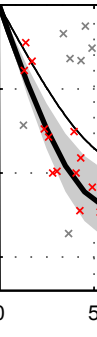


Figure 4. 
Figure 5. 
(a) $v_{c}(r, z)\left[\mathrm{cm} \mathrm{s}^{-1}\right]$

(b)

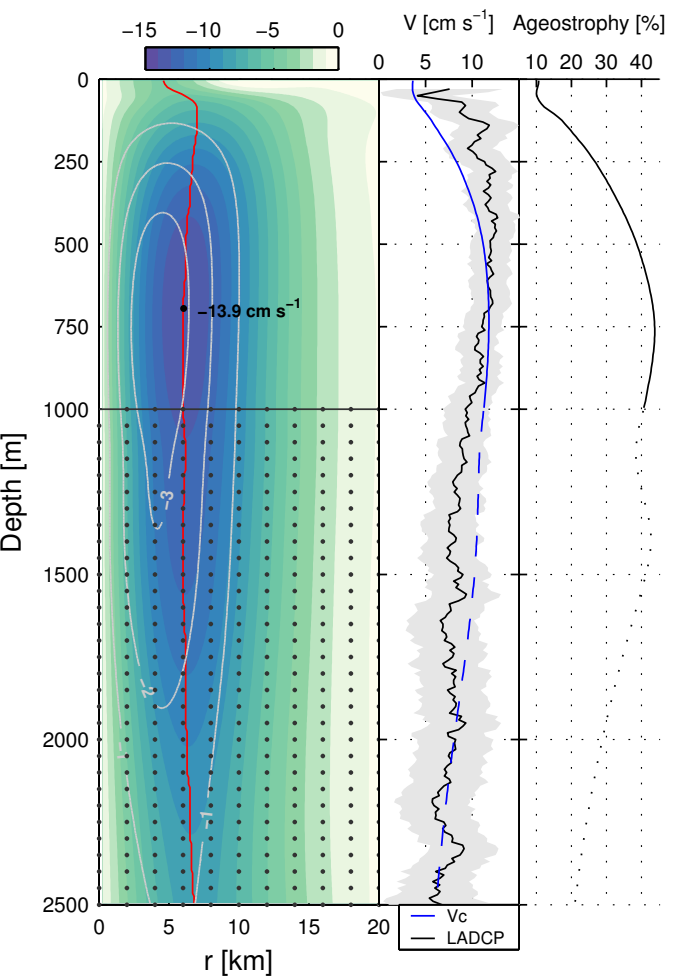

(c) $\mathrm{N}(\mathrm{r}, \mathrm{z}) / \mathrm{N}_{\text {out }}(\mathrm{z})$

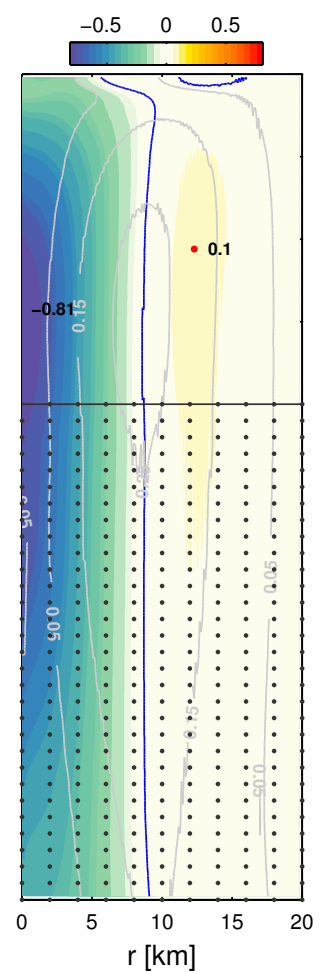

(d) $\mathrm{q}(\mathrm{r}, \mathrm{z}) / \mathrm{q}_{\text {out }}(\mathrm{z})$

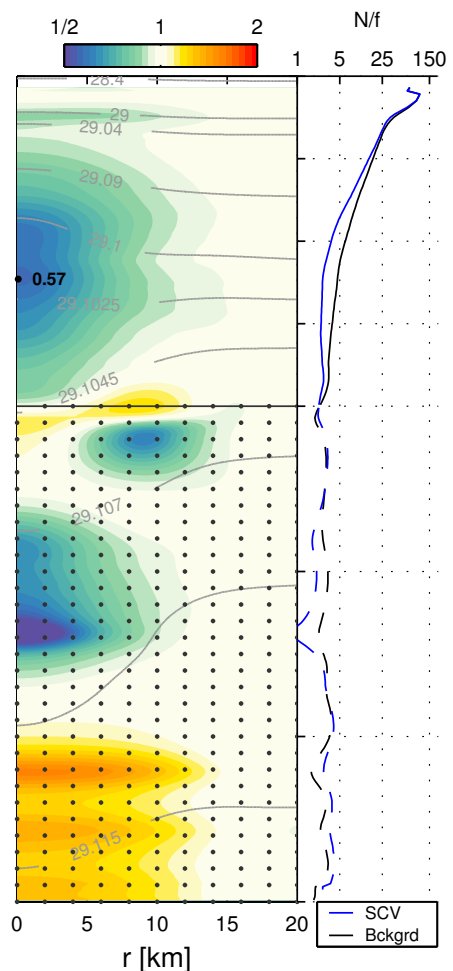

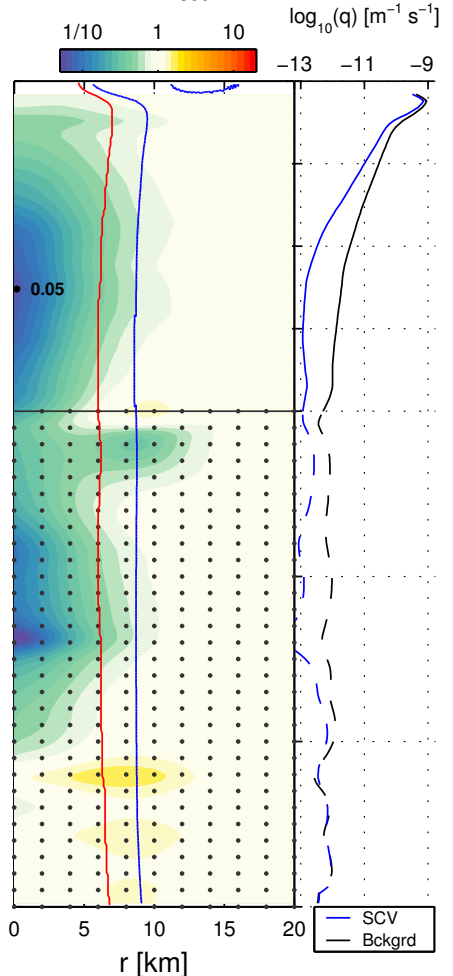


Figure 6. 
(a)
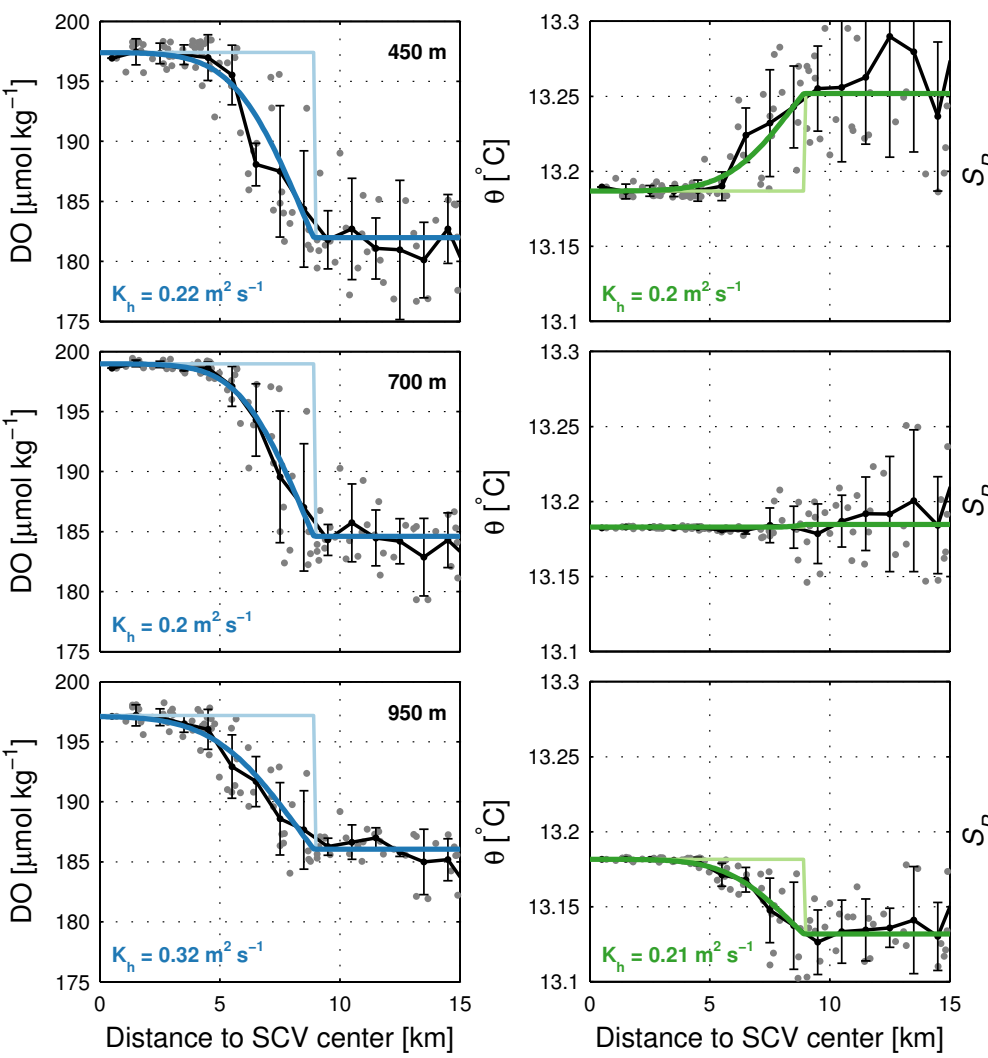

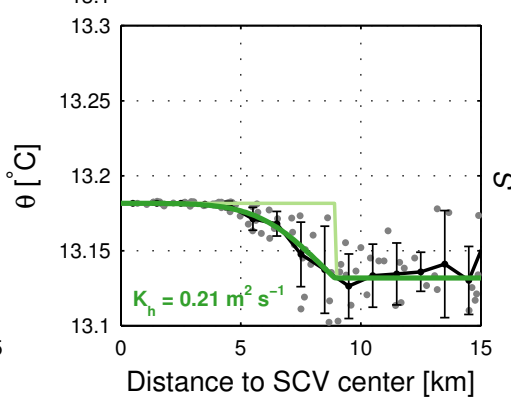

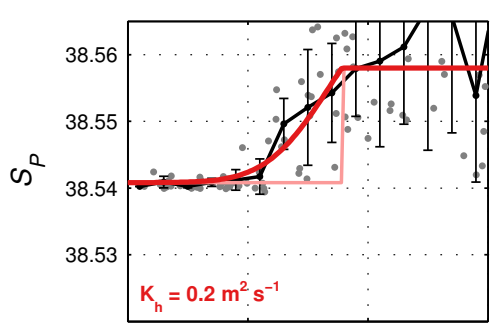

(b)
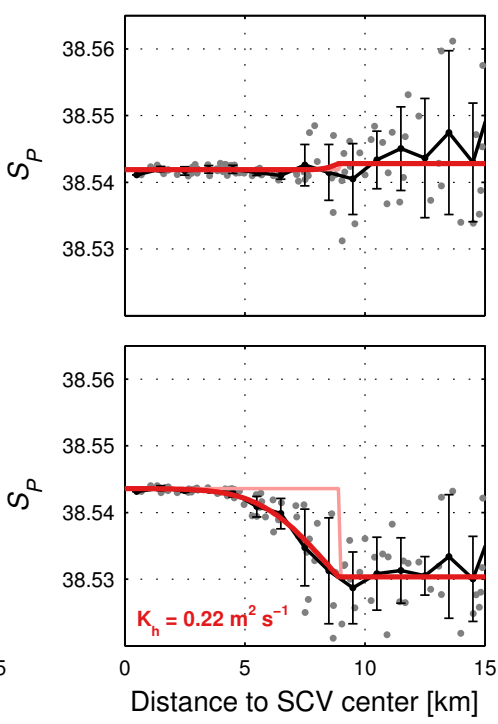

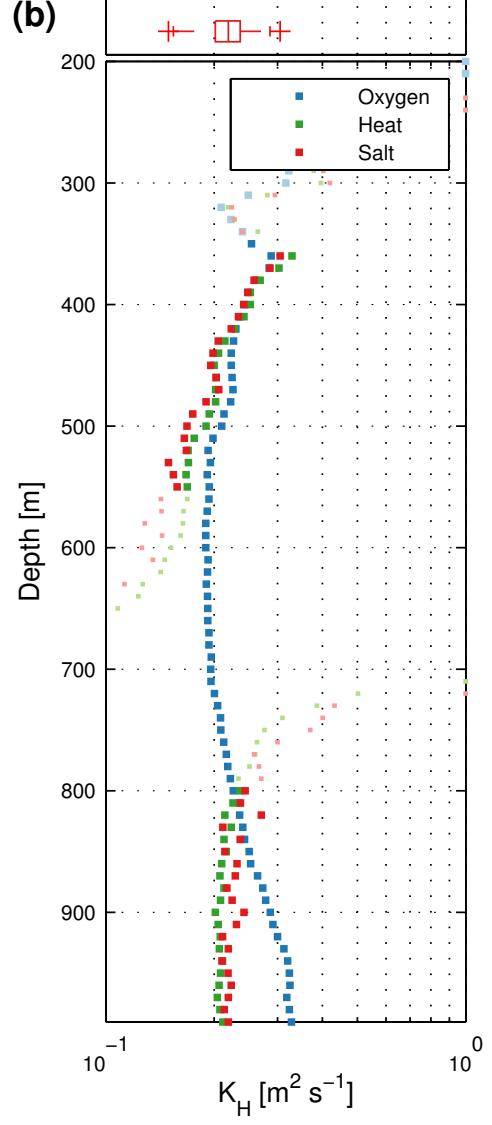


Figure 7. 


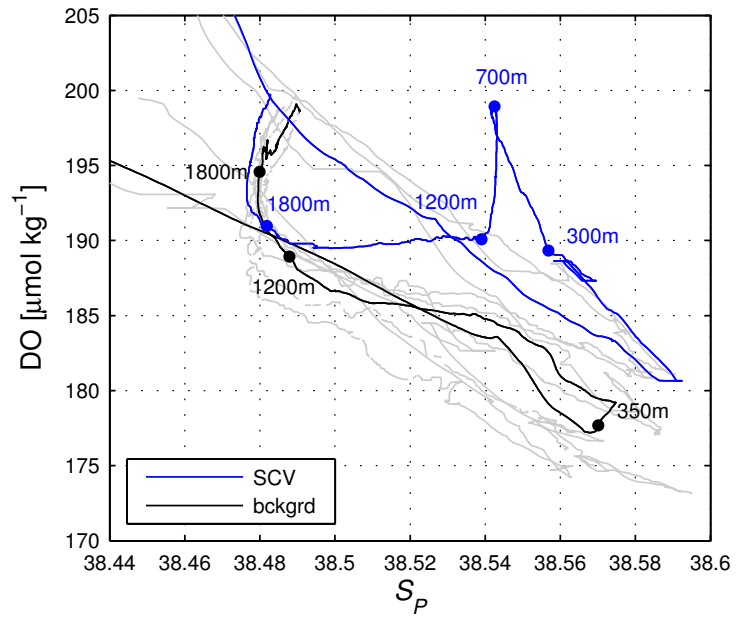


Figure 8. 
(a)
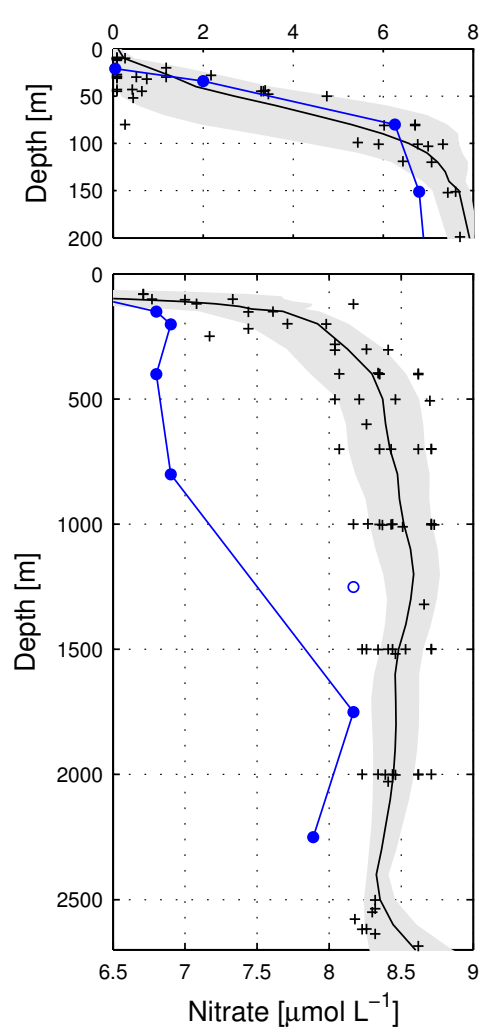

(b)
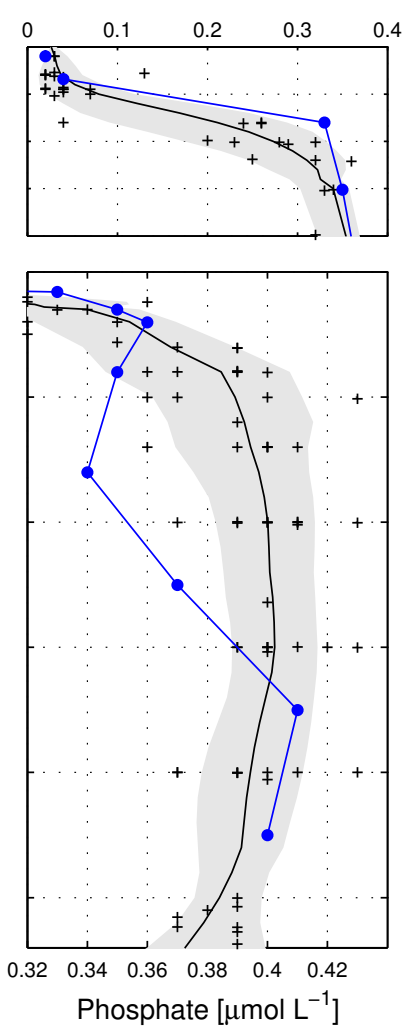

(c)
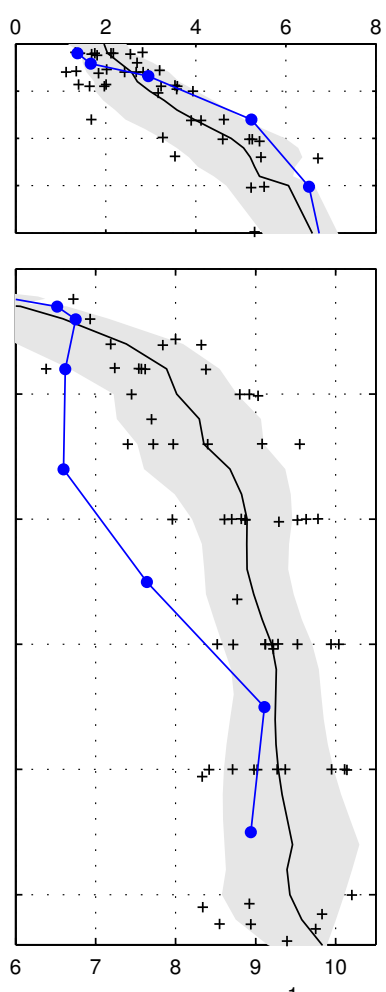

Silicate $\left[\mu \mathrm{mol} \mathrm{L}{ }^{-1}\right]$ (d)
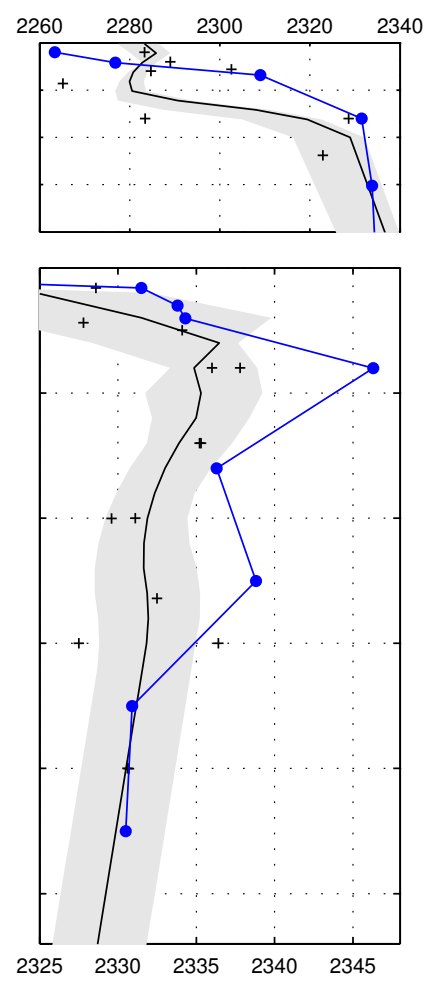

Dissolved inorganic carbon $\left[\mu \mathrm{mol} \mathrm{kg}{ }^{-1}\right]$ 
Figure 9. 
Figure 10. 
